\title{
GMR
}

\section{Effect of ozone on vascular endothelial growth factor (VEGF) and related inflammatory cytokines in rats with diabetic retinopathy}

\author{
T.Y. Xie, W. Yan, J. Lou and X.Y. Chen \\ Department of Ophthalmology, \\ The First Affiliated Hospital of Xinjiang Medical University, Urumchi, China \\ Corresponding author: X.Y. Chen \\ E-mail: xueyichendoc@126.com \\ Genet. Mol. Res. 15 (2): gmr. 15027558 \\ Received August 31, 2015 \\ Accepted February 12, 2016 \\ Published May 13, 2016 \\ DOI http://dx.doi.org/10.4238/gmr.15027558
}

\begin{abstract}
The aim of this study was to investigate the effect of ozone on inflammatory cytokines in diabetic retinopathy (DR) rats. Male rats (40) weighing 300-360 g were included in this study. Thirty rats were randomly divided into the model and ozone groups after DR was induced by streptozotocin. Ten rats served as the blank group. After the diabetic models were established for one month, the rats in the ozone group were treated with $50 \mathrm{mg} / \mathrm{kg}$ ozone coloclysis for one month (three times a week). After the rats were anesthetized by intraperitoneal injection, blood samples from the abdominal aorta were collected, and the supernatant was obtained by centrifugation. Vascular endothelial growth factor (VEGF) and inflammatory cytokine content in the serum was detected by enzyme linked immunosorbent assay. The values of VEGF, intercellular cell adhesion molecule-1, interleukin-1 beta, tumor necrosis factor- $\alpha$, and IL- 6 were significantly different among the three groups $(\mathrm{P}<0.05)$. The cytokine levels in the model group were higher than those in the blank group $(\mathrm{P}<0.05)$. The level
\end{abstract}


of each cytokine in the ozone group was higher than that in the blank group. Compared with the model group, the cytokine levels in the ozone group were significantly reduced $(\mathrm{P}<0.05)$. Ozone had no effect on the blood glucose of diabetic rats. Treatment with ozone coloclysis may effectively reduce the secretion of VEGF and inflammatory cytokines in diabetic retinopathy rats.

Key words: Diabetic retinopathy; Ozone treatment; VEGF; Inflammatory cytokines

\section{INTRODUCTION}

Diabetic retinopathy (DR) is one of the common microvascular complications of diabetes, and it has become the leading cause of blindness in young adults in developed countries (Zhang et al., 2010; Antonetti et al., 2012). In addition to the early control of blood glucose (UK Prospective Diabetes Study Group, 1998), therapies include laser treatment, vitreous cut surgery, and the use of anti-VEGF in nonproliferative retinopathy and proliferative retinopathy, but the effects are unsatisfactory. A clinical study found that people with diabetes have 'metabolic memory'. When cells were immersed in a highglucose environment for a period, the inflammatory cytokines and white blood cells that increased could not recover, and controlling blood glucose did not completely inhibit the inflammation induced by previous high-glucose exposure (Ihnat et al., 2007). Meanwhile, studies also confirmed that the pathological features and development process of DR indicate low-grade chronic inflammation (Adamis, 2002). Research has also shown that the levels of tumor necrosis factor (TNF)- $\alpha$, interleukin-1 beta (IL-1 $\beta$ ), IL-6, and intercellular cell adhesion molecule-1 (ICAM-1) in DR patients' serum and vitreous retinas were significantly higher than those in non-diabetic patients, and this was positively correlated with the severity of fertile DR (Joussen et al., 2004; Kaštelan et al., 2007; Myśliwiec et al., 2008; Aveleira et al., 2010; Wiwanitkit, 2011). Inflammatory cytokines triggered by highglucose may be one contributing factor to the development of complications related to diabetes under the despite stable control of blood glucose. Hence, blocking the occurrence of metabolic memory through the use of anti-inflammatory and antioxidant agents can delay the development of DR. As early as 1964, Powell and Field (1964) found that patients with arthritis who took anti-inflammatory drugs had less tendency to develop severe diabetes in clinical observations (King, 2008). Because of the non-specific chronic inflammation, however, it is difficult to control the development of DR using anti-inflammatory drugs. Therefore, it is important to find a safer anti-inflammatory agent for the prevention and control of DR.

Ozone is an allotrope made up of three oxygen atoms and is a type of broad-spectrum and high-efficient disinfectant. Its oxidation is extremely strong, and ozone has a very good sterilizing effect; during the Second World War, ozone was widely used for treatment of infection caused by injuries. Further studies have shown that ozone has anti-inflammatory and antioxidant effects, inhibits cell apoptosis, and helps with immune regulation (Calunga et al., 2005; Chen et al., 2008). Ozone can reduce inflammation damage by regulating the 
inflammatory mediators (IL-6, IL-8) and the expression of cytokines (TNF- $\alpha$ ) (Di Filippo et al., 2008). The present study aimed to understand the effect of ozone on inflammatory cytokines and as a treatment for DR in a diabetic rat model.

\section{MATERIAL AND METHODS}

\section{Animals}

Sprague-Dawley (SD) male rats used in this study were provided by the animal experiment center of Xinjiang Medical University [license: SCXK (new) 2003-0001]. This study was carried out in strict accordance with the recommendations in the Guide for the Care and Use of Laboratory Animals of the National Institutes of Health. The animal use protocol has been reviewed and approved by the Institutional Animal Care and Use Committee (IACUC) of the First Affiliated Hospital of Xinjiang Medical University (ethical review number: protocol 09-030).

\section{Establishment of the rat diabetic model}

SD male rats (40) (300-360 g) aged 12-16 weeks were fed adaptably for 1 month. Ten rats were randomly selected for the normal control group and fed with normal feed. The remaining rats (30) were fed high fat and glucose feed (15\% fat, $18 \%$ glucose, $2 \%$ egg yolk, $0.2 \%$ bile salts, $62.8 \%$ normal feed) for 45 days, were fasted but watered after $12 \mathrm{~h}$, and administered $30 \mathrm{mg} / \mathrm{kg}$ streptozotocin (STZ, $10 \mathrm{~g} / \mathrm{L}$, Sigma company, USA) diluted with sterile fresh citrate buffer $(0.1 \mathrm{mM}, \mathrm{pH} 4.3-4.5)$ to establish the diabetic rat model via onetime intraperitoneal injection. At $24 \mathrm{~h}$ after injection, the blood glucose was detected by taking blood from the tail (SumStep glucosemeter, Johnson \& Johnson). An average fasting glucose $\geq 11.1 \mathrm{mM}$ was considered standard, and rats that did not meet the standard were administered another injection. Rats that still did not meet the standard were removed from the study, and thus, $23 \mathrm{SD}$ rats remained. Rats were weighed and blood glucose was tested regularly.

\section{Grouping}

After observing the blood glucose and weight changes for 1 month, the model rats were randomly divided into two groups. The diabetes model control group $(\mathrm{N}=11)$ was not given any intervention. In the ozone treatment group $(\mathrm{N}=12)$, a mixture of ozone (concentration of $50 \mu \mathrm{g} / \mathrm{mL}$, produced by ozone generating apparatus, Germany) was slowly infused into the rectum, after emptying, at about $0.5 \mathrm{~cm}$, with a dosage of $0.5 \mathrm{mg} / \mathrm{kg}$. The apparatus was pressed against the anus for $5 \mathrm{~min}$ to prevent gas emission. The treatment was repeated three times a week, and the course of treatment was one month.

\section{Sampling}

After a period of ozone treatment, chloral hydrate $(0.3 \mathrm{~mL} / 100 \mathrm{~g}, 0.5 \%$ chloral hydrate $)$ (Department of Pharmaceutical, the First Affiliated Hospital of Xinjiang Medical University) was injected into the abdomens of rats in each group. The eyeballs were removed after anesthesia and were cut along the angle of the sclera edge on ice using a microscope. The front section and 
part of the vitreum were removed and the bilateral retinal tissue was stripped rapidly and placed in a freeze pipe, frozen with liquid nitrogen for $10 \mathrm{~min}$, and stored at $-80^{\circ} \mathrm{C}$. After removing the eyeballs, the belly line was incised, separated bluntly to reveal the abdominal aorta, and the arterial blood was collected. The supernatant was centrifuged at $-80^{\circ} \mathrm{C}$.

\section{Measurement with ELISA}

The balanced ELISA Kit (VEGF Rat ELISA Kit (Abcam, Lot: GR148932-1 batch No.: ab100786), ELISA kit for IL-1 $\beta$ (Cloud-Clone Corp; article No.: SEA563Ra; batch No.: L140116385), ICAM-1 Rat Elisa Kit (Abcam, Lot: GR125560-1; batch No.: ab100763), IL-6 Rat Elisa Kit (Lifetech, Lot: 1449842A; batch No.: KRC0061), and TNF- $\alpha$ Rat Elisa Kit (Life technologies, Lot: 1290859B; batch No.: KRC3011) were used to determine cytokine levels. Samples were thawed at room temperature for $30 \mathrm{~min}$ and centrifuged (Shanghai Lishen Scientific instrument Co., LTD.; batch No.: Neofuge 15R) at $4^{\circ} \mathrm{C}, 12,000 \mathrm{rpm}$ for $5 \mathrm{~min}$. Samples were diluted to the appropriate concentration. To each well, $100 \mu \mathrm{L}$ standard or sample was added, and the plate was sealed with a seal membrane. The plate was then shaken on a micro oscillator (Medical instrument factory; Jintan city, model: MM-2) at room temperature for $2.5 \mathrm{~h}$. The membrane was carefully removed and the plate was dried. Subsequently, $300 \mu \mathrm{L}$ detergent was added to each well, removed after $2 \mathrm{~min}$, and the plate patted dry. This was repeated five times. Then, $100 \mu \mathrm{L}$ 1X Biotinylated ICAM1 detection antibody was prepared and added to each well. The plate was shaken at room temperature for $1 \mathrm{~h}$, liquid removed, $300 \mu \mathrm{L}$ detergent added to each well, removed after $2 \mathrm{~min}$, and plate patted dry. This was repeated five times. Then, $100 \mu \mathrm{L}$ 1X HRP-Streptavidin solution was added to each well, the plate was shaken for $45 \mathrm{~min}$, and the liquid was removed. Again, $300 \mu \mathrm{L}$ detergent was added to each well, removed after $2 \mathrm{~min}$, and the plate patted dry, repeating five times. TMB One-Step Substrate $(100 \mu \mathrm{L})$ was added to each well and the plate was shaken away from light for $30 \mathrm{~min}$. Stop solution $(50 \mu \mathrm{L})$ was added to each well to end the reaction, and the wavelength optical density value (OD value) of each well was determined at $450 \mathrm{~nm}$ with a microplate reader (Bio-rad, xMarkTM) after $5 \mathrm{~min}$. The results were processed using ELISA data processing software.

\section{Statistical analysis}

The SPSS17.0 software was used for the statistical analysis, and the data are reported as means $\pm \mathrm{SD}$. The homogeneity test of variance was performed on each sample mean. The expression of each factor in each group was used in the single factor level design analysis of variance. For pairwise comparisons, the LSD $t$-test was used and groups with heterogeneity of variance were tested using the Dunnett $\mathrm{T} 3$ test. $\mathrm{P}<0.05$ was considered statistically significant.

\section{RESULTS}

\section{General health}

After 1 week, SD rats began to exhibit increased drinking, eating, and polyuria. One month later, urine volume decreased, rat weights decreased, and there was an increase in blood glucose (Figure 1). The color of the rat tail began to darken, indicating a state of high blood glucose. The weight and blood glucose levels of the zone and model groups before and after 
induction were not significantly different, indicating a successful model (weight: $t=1.796$, $\mathrm{P}>1.796$; blood glucose $t=1.714, \mathrm{P}>1.714)$. After treatment with ozone, the weight and blood glucose of the two groups was not statistically different (weight: $t=0.105, \mathrm{P}>0.105$; blood glucose: $t=1.387, \mathrm{P}>1.387$ ) indicating that the ozone treatment had no effect on blood glucose and weight (Table 1).
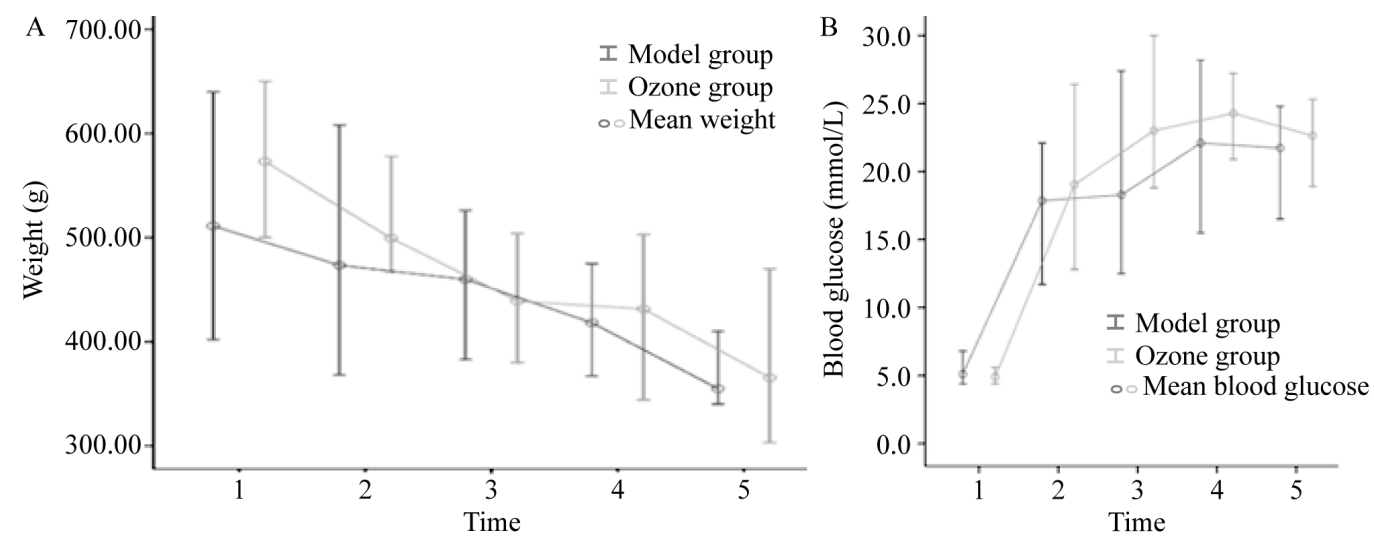

Figure 1. Changes in rat weight and blood glucose in the model and ozone groups. 1: Before modeling, 2: modeling, 3: one week after modeling, 4: one month after modeling, 5: before sacrifice.

Table 1. Changes of blood sugar and weight of rats in model group and ozone group.

\begin{tabular}{l|c|c|c|c}
\hline \multirow{2}{*}{ Time point } & \multicolumn{2}{|c|}{ Blood sugar $(\mathrm{mM})$} & \multicolumn{2}{c}{ Weight $(\mathrm{g})$} \\
\cline { 2 - 5 } & Model group & Ozone group & Model group & Ozone group \\
\hline Before modeling & $5.14 \pm 0.14$ & $4.9 \pm 0.49$ & $511.2 \pm 80.69$ & $573.12 \pm 47.12$ \\
\hline Model establishment & $17.85 \pm 3.21$ & $19.03 \pm 3.87$ & $473.4 \pm 78.38$ & $499.37 \pm 50.84$ \\
\hline 1 week after modeling & $18.28 \pm 4.3$ & $23 \pm 3.46$ & $459.8 \pm 51.06$ & $439 \pm 40.71$ \\
\hline 1 month after modeling & $22.09 \pm 3.3$ & $24.27 \pm 2.22$ & $418.2 \pm 40.68$ & $431.37 \pm 52.81$ \\
\hline Sacrifice & $21.72 \pm 2.54$ & $22.62 \pm 2.53$ & $354.9 \pm 21.11$ & $365.5 \pm 48.57$ \\
\hline
\end{tabular}

\section{ELISA}

The inflammatory cytokines presented in different levels in the serum. The $95 \%$ confidence intervals of the blank group were 2.51-6.06 pg/mL for VEGF, 74.89-134.14 pg/ $\mathrm{mL}$ for ICAM-1, $1.97-12.33 \mathrm{pg} / \mathrm{mL}$ for TNF- $\alpha, 5.54-7.76 \mathrm{pg} / \mathrm{mL}$ for IL-1 $\beta$, and 36.96-51.51 $\mathrm{pg} / \mathrm{mL}$ for IL-6. Five kinds of inflammatory cytokines between the three groups exhibited significant differences in serum levels (VEGF: $F=62.249$; IL-1 $\beta$ : $F=43.00$; IL-6: $F=$ 54.63; TNF- $\alpha$ : 58.03; ICAM-1: $\mathrm{F}=29.75, \mathrm{P}<0.05)$. Compared with the blank group, each cytokine in the model group was increased $(\mathrm{P}<0.05)$, with TNF- $\alpha$ and IL-6 increasing 7.85 and 3.58 times the blank group, respectively $(\mathrm{P}<0.05)$ (Figure 2) (Table 2). Compared with the model group, each cytokine level was decreased in the ozone group. IL-6 levels fell nearly $30 \%(\mathrm{P}<0.05)$, and the levels of VEGF, IL-1 $\beta$, and IL-6 were close to those of the blank control group. There was no significant difference between the level of IL-6 in the blank and ozone groups $(\mathrm{P}>0.05)$. 


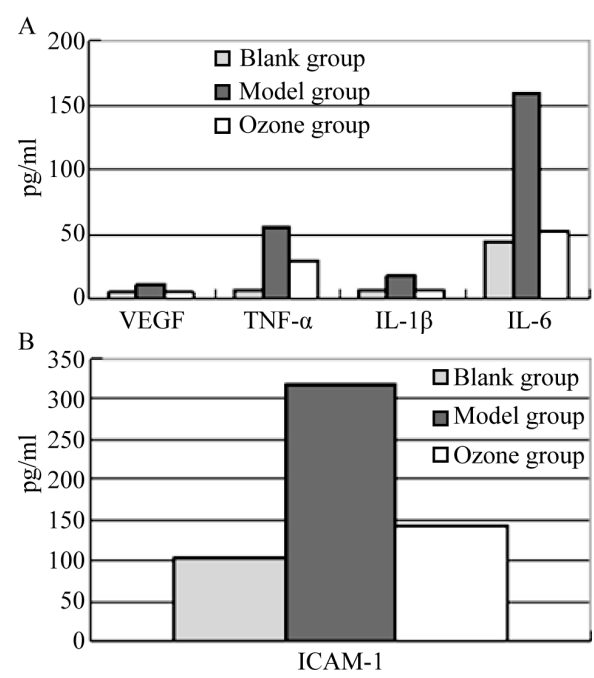

Figure 2. Expression of related inflammation cytokines in the serum of rats.

Table 2. Expression of related inflammation cytokines in serum of rats (means $\pm \mathrm{SD}$ ).

\begin{tabular}{l|c|c|c|c|c}
\hline Group & VEGF $(\mathrm{pg} / \mathrm{mL})$ & TNF- $\alpha(\mathrm{pg} / \mathrm{mL})$ & ICAM- $1(\mathrm{ng} / \mathrm{mL})$ & IL-1 $\beta(\mathrm{pg} / \mathrm{mL})$ & $\mathrm{IL}-6(\mathrm{pg} / \mathrm{mL})$ \\
\hline Blank group & $4.29 \pm 1.11$ & $7.15 \pm 3.25$ & $104.51 \pm 18.61$ & $6.65 \pm 0.69$ & $44.23 \pm 4.57$ \\
\hline Model group & $12.1 \pm 1.62^{\#}$ & $56.18 \pm 11^{\#}$ & $317.16 \pm 73.84^{\#}$ & $17.28 \pm 3.71^{\#}$ & $158.42 \pm 34.57^{\#}$ \\
\hline Ozone group & $4.44 \pm 1.76^{*}$ & $29.56 \pm 4.4^{*}$ & $142.16 \pm 41.99^{*}$ & $7.01 \pm 0.78^{*}$ & $52.15 \pm 8.07^{*}$ \\
\hline
\end{tabular}

${ }^{\#}$ Compared with the blank group, $\mathrm{P}<0.001$; ${ }^{*}$ Compared with model group, $\mathrm{P}<0.001$.

\section{DISCUSSION}

The pathogenesis of diabetic retinopathy is not fully understood. Animal experiments have shown that retinal blood vessels of diabetic rats induced by STZ show signs of inflammatory response, such as leukocyte adhesion and infiltration, which is intensified throughout the course of the disease (Chibber et al., 2007). Clinical trials have shown that patients with diabetes were in a mild inflammation and stress state, which can cause activation of the body's immune system, mainly an increase in phagocytes and peripheral lymphocytes, the activation of immune cells in the blood plasma, and an increase in the concentrations of pro-inflammatory cytokines such as PGE2, IL-1 $\beta$, IL-2, and IL-6. Therefore, researchers have suggested that diabetes is a chronic low-grade inflammatory and autoimmune disease (Doganay et al., 2002). High blood glucose can cause leukocyte adhesion to vascular endothelial cells, resulting in destruction of the blood retinal barrier (BRB), and a high level of TNF- $\alpha$ in blood circulation can be obtained in retinal blood vessels only through crossing the destroyed BRB and inducing the expression of ICAM-1. At the same time, the increasing accumulation of leukocyte adhesion in the capillaries forms small emboli that block capillaries and release a variety of active substances, which aggravate microcirculation, while the hypoxia state of the retina stimulates the expression of VEGF. This upregulates the expression of vascular endothelial adhesion factors (such as ICAM-1) and IL-1 $\beta$, which further aggravates the 
hypoxia state, leading to DR (Doganay et al., 2002), constituting a vicious cycle. There are many inflammatory factors and mediators involved in the development of DR, and they play an important role in the disease prognosis. Thus, preventing inflammation is necessary for controlling the occurrence and development of DR.

Combined with the unsaturated fatty acids in the bacterial cell membranes, ozone can oxidize intracellular enzyme protein, RNA, and DNA, and change the cell permeability, which results in inactivation and the dissolution of dead bacteria. In theory, DR is an ischemia and anoxia disease involving chronic low-grade inflammation. The anti-inflammatory and immune enhancing functions of ozone are relevant to the pathogenesis of DR. A large number of clinical experiments have established that ozone can improve ischemia-reperfusion injury (Stadlbauer et al., 2008), accelerate healing of the diabetic foot (Wainstein et al., 2011), and improve diabetic nephropathy (Morsy et al., 2010). This research focused mainly on exploration of the therapeutic effect of ozone on DR from the angle of inflammatory cytokines.

VEGF is a growth factor that now is closely related to the occurrence and development of DR, and high expression of VEGF can cause pathological changes, such as destruction of the BRB and formation of new blood vessels. Therefore, anti-VEGF therapies can effectively alleviate middle-late DR. In this study, the level of VEGF in the model group was three times higher than that of the blank group and stayed high, which confirmed that the content of VEGF in 2-month STZ rat serum had begun to rise. Noma et al. (2002) showed that a VEGF content that is increased by three times indicates the proliferative DR period. The content of VEGF in the ozone group was lower than that of the model group and the difference was statistically significant, proving that ozone treatment can effectively reduce the expression of VEGF. Hence, ozone can also be considered an anti-VEGF treatment. In this study, VEGF was detected in the blank control group, and a certain amount of VEGF is necessary for blood vessels to maintain normal function (Malone et al., 2001). However, high expression of VEGF can lead to a series of pathological changes. There is controversy regarding whether the level of VEGF in the serum is representative of the content in the retina. There are studies claiming that VEGF of the retina is derived from the retina itself, rather than the circulation of blood (Storkebaum et al., 2004; Semeraro et al., 2014). Our results showed high expression of VEGF in both the retina and serum of 2-month diabetic rats, suggesting that VEGF in the serum does reflect the content of VEGF in the retina to a certain degree.

Leukocyte adhesion to the retinal vasculature is thought to be associated with endothelial cell death, capillary occlusion, and increased vascular permeability, which all contribute to the progression of diabetic retinopathy (Krieglstein and Granger, 2001). Therefore, adhesion molecules play an important role in DR. Previous studies reported that the increased number of adherent leukocytes in the diabetic retina is mediated by the concomitant increase in ICAM-1 expression in the retinal vasculature (Zhang et al., 2009). Therefore, ICAM1 represents the initiation of vascular lesions in early DR, and it is mutually reinforced by the expression of VEGF. Similar to other reported results, this study also showed that the serum content of ICAM-1 of the model group was three times higher than that of the blank group, confirming that even 2-month diabetic rats had started the process of inflammation with endothelial injuries of the blood capillary. After treatment with ozone, the content of ICAM1 was slightly higher than that of the blank control group and was far lower than the model group, and there was no statistically significant difference between the ozone treatment group and the blank group. This confirmed that ozone can inhibit the early adhesion of white blood cells in diabetic rat serum, relieve capillary endothelial injury, and block the synergetic effect 
of ICAM-1 and VEGF, which is very important for delaying the development of DR.

TNF- $\alpha$ is a multi-functional inflammatory cytokine produced by mononuclear macrophages, lymphocytes, and endothelial cells (Behl et al., 2008; Gustavsson et al., 2008). TNF- $\alpha$ can cause impairment of vasodilation through nitric oxide (NO) damage, leading to endothelial dysfunction and microvascular lesions. In addition, TNF- $\alpha$ can stimulate stasis of white blood cells, improve permeability of retinal vasculature by directly damaging the BRB, stimulate macrophages and other cells to produce cytokines, such as IL-6 and IL-8, enhance the local inflammatory response in the retina, and increase the expression of VEGF. The results showed that compared with the blank control group, the content of TNF- $\alpha$ increased significantly, but compared with the model group, there was a decrease, showing that ozone can inhibit the release of TNF- $\alpha$. TNF- $\alpha$ remains an independent determinant factor for PDR (Gustavsson et al., 2008), and ozone inhibits DR via anti-inflammatory actions. Therefore, ozone reducing the content of TNF- $\alpha$ of DM rats can maintain the blood retinal barrier to some extent and decrease the expression of other relevant inflammation cytokines.

IL-1 $\beta$ is a proinflammatory cytokine with bone-marrow-stimulating properties, and it can exacerbate the expression of other cytokines and adhesion molecules (Liu et al., 2012). Similar to previous results (Cassel and Sutterwala, 2010; Vandanmagsar et al., 2011), this study showed that IL-1 $\beta$ could be detected in the peripheral serum of STZ rats in the blank control group. Meanwhile, the level in the model group also increased two times that of the blank group, and after ozone treatment, there was a decrease to close to that of the blank group. Studies have shown that IL-1 $\beta$ cannot be detected in the peripheral blood (Gustavsson et al., 2008), but we showed that even a small amount of IL-1 $\beta$ was detected in the peripheral serum of healthy rats. This could be attributed to the use of different subjects or experimental methods and should be confirmed by further studies. However, this study showed that ozone can reduce the content of IL- $1 \beta$, reduce the adhesion of leukocytes, protect capillaries, and block inflammatory cytokine release.

IL-6, a proinflammatory cytokine, is a main inductive factor in the acute phase of reaction to infection or trauma. IL-6 has a direct toxic effect on islet cells, accelerating the onset of diabetes (Yuuki et al., 2001; Spranger et al., 2003; Joussen et al., 2004). Concomitantly, under the effect of IL-1 induced by reactive oxygen species (ROS), IL-6 can prompt the expression of ICAM-1, causing further damage to endothelial cells. Cohen et al. (1996) believed that IL-6 had a synergistic effect on IL- $1 \beta$ and TNF- $\alpha$, and IL- 6 can directly induce the expression of VEGF (Ishida et al., 2003), leading to the generation of retinal neovascularization. Thus, IL-6 not only is an important factor in the acute phase of inflammation, but also plays an important role in the subsequent process of low-grade chronic inflammation. The results also showed that the content of IL-6 in the model control group was 3-4 times that of the blank control group, confirming that it was presented as an acute inflammatory process in 2-month DM rat serum. After treatment with ozone, the content of IL- 6 in the rat serum was $8 \mathrm{pg} / \mathrm{mL}$ higher than that of the blank control group, and significantly lower than the model control group, which suggested that ozone can control the expression of IL-6.

Studies have determined that TNF- $\alpha$ can be an independent influence factor in PDR (Gustavsson et al., 2008), and that VEGF is positively related to ICAM-1, IL-1 $\beta$, and IL-6 (Cohen et al., 1996; Joussen et al., 2002; Ishida et al., 2003; Moore et al., 2003; Chan et al., 2010). Our study had similar results. The cytokine levels were increased in the model group compared to the control, and this was positively correlated with VEGF. Therefore, ozone has an inhibitory effect on other related inflammatory cytokines. The effect of ozone is enhanced by its inhibition of several cytokines, demonstrating why ozone is commonly used as an anti-inflammatory agent. 


\section{CONCLUSION}

The experiment showed that VEGF and other inflammatory factors in the serum of 2-month rats induced by STZ increased, indicating that the inflammatory response plays a role in the development of DR before clinical manifestations appear explicitly. Inhibition of VEGF and inflammatory mediators with ozone confirmed that ozone decreases the expression of related inflammatory cytokines in the retina and serum of early DM rats, reducing inflammation and halting the development of DR. This research showed that ozone had no influence on blood glucose, while inhibiting inflammatory cytokine release, revealing that the mechanism of ozone is not lowering blood glucose.

The limitations of this study were few samples, short course of treatment (only one course of treatment), and although enema treatment is easy to implement, dosage is not easy to control (Koleva-Georgieva et al., 2011). However, it is clear that ozone indeed inhibited the release of inflammatory mediators in the serum of DM rats. Although many clinicians have concerns about the side effects of ozone, such as respiratory stimulation, when used correctly, ozone is safe. The ozone generator is simple to operate, and it is low-cost and readily available, making it an ideal treatment for patients with DR in developing countries. Ozone has been used for the treatment of hypoxic-ischemic disease, ischemic-reperfusion injury, age-related macular degeneration, and diabetic foot in many countries with satisfactory results. Thus, the results in this study will provide the foundation for future in vivo experiments, providing further evidence for the value of ozone in the clinic.

\section{Conflicts of interest}

The authors declare no conflicts of interest.

\section{ACKNOWLEDGMENTS}

Research supported by the Natural Scientific Research Fund Project of Xinjiang Uygur Autonomous Region (\#2014211C046).

\section{REFERENCES}

Adamis AP (2002). Is diabetic retinopathy an inflammatory disease? Br. J. Ophthalmol. 86: 363-365. http://dx.doi. org/10.1136/bjo.86.4.363

Antonetti DA, Klein R and Gardner TW (2012). Diabetic retinopathy. N. Engl. J. Med. 366: 1227-1239. http://dx.doi. org/10.1056/NEJMra1005073

Aveleira CA, Lin CM, Abcouwer SF, Ambrósio AF, et al. (2010). TNF- $\alpha$ signals through PKC $\zeta / N F-\kappa B$ to alter the tight junction complex and increase retinal endothelial cell permeability. Diabetes 59: 2872-2882. http://dx.doi. org $/ 10.2337 / \mathrm{db} 09-1606$

Behl Y, Krothapalli P, Desta T, DiPiazza A, et al. (2008). Diabetes-enhanced tumor necrosis factor-alpha production promotes apoptosis and the loss of retinal microvascular cells in type 1 and type 2 models of diabetic retinopathy. Am. J. Pathol. 172: 1411-1418. http://dx.doi.org/10.2353/ajpath.2008.071070

Calunga JL, Zamora ZB, Borrego A, Río Sd, et al. (2005). Ozone therapy on rats submitted to subtotal nephrectomy: role of antioxidant system. Mediators Inflamm. 2005: 221-227.http://dx.doi.org/10.1155/MI.2005.221

Cassel SL and Sutterwala FS (2010). Sterile inflammatory responses mediated by the NLRP3 inflammasome. Eur. J. Immunol. 40: 607-611.http://dx.doi.org/10.1002/eji.200940207

Chan PS, Kanwar M and Kowluru RA (2010). Resistance of retinal inflammatory mediators to suppress after reinstitution of good glycemic control: novel mechanism for metabolic memory. J. Diabetes Complications 24: 55-63. http:// dx.doi.org/10.1016/j.jdiacomp.2008.10.002 
Chen H, Xing B, Liu X, Zhan B, et al. (2008). Ozone oxidative preconditioning inhibits inflammation and apoptosis in a rat model of renal ischemia/reperfusion injury. Eur. J. Pharmacol. 581: 306-314. http://dx.doi.org/10.1016/j. ejphar.2007.11.050

Chibber R, Ben-Mahmud BM, Chibber S and Kohner EM (2007). Leukocytes in diabetic retinopathy. Curr. Diabetes Rev. 3: 3-14. http://dx.doi.org/10.2174/157339907779802139

Cohen T, Nahari D, Cerem LW, Neufeld G, et al. (1996). Interleukin 6 induces the expression of vascular endothelial growth factor. J. Biol. Chem. 271: 736-741. http://dx.doi.org/10.1074/jbc.271.2.736

Di Filippo C, Marfella R, Capodanno P, Ferraraccio F, et al. (2008). Acute oxygen-ozone administration to rats protects the heart from ischemia reperfusion infarct. Inflamm. Res. 57: 445-449. http://dx.doi.org/10.1007/s00011-008-7237-0

Doganay S, Evereklioglu C, Er H, Türköz Y, et al. (2002). Comparison of serum NO, TNF-alpha, IL-1beta, sIL-2R, IL-6 and IL-8 levels with grades of retinopathy in patients with diabetes mellitus. Eye (Lond.) 16: 163-170.http://dx.doi. org/10.1038/sj/eye/6700095

Gustavsson C, Agardh E, Bengtsson B and Agardh CD (2008). TNF- $\alpha$ is an independent serum marker for proliferative retinopathy in type 1 diabetic patients. J. Diabetes Complications 22: 309-316. http://dx.doi.org/10.1016/j. idiacomp.2007.03.001

Ihnat MA, Thorpe JE, Kamat CD, Szabó C, et al. (2007). Reactive oxygen species mediate a cellular 'memory' of high glucose stress signalling. Diabetologia 50: 1523-1531. http://dx.doi.org/10.1007/s00125-007-0684-2

Ishida S, Usui T, Yamashiro K, Kaji Y, et al. (2003). VEGF164 is proinflammatory in the diabetic retina. Invest. Ophthalmol. Vis. Sci. 44: 2155-2162.http://dx.doi.org/10.1167/iovs.02-0807

Joussen AM, Poulaki V, Le ML, Koizumi K, et al. (2004). A central role for inflammation in the pathogenesis of diabetic retinopathy. FASEB J. 18: 1450-1452.

Joussen AM, Poulaki V, Qin W, Kirchhof B, et al. (2002). Retinal vascular endothelial growth factor induces intercellular adhesion molecule-1 and endothelial nitric oxide synthase expression and initiates early diabetic retinal leukocyte adhesion in vivo. Am. J. Pathol. 160: 501-509. http://dx.doi.org/10.1016/S0002-9440(10)64869-9

Kaštelan S, Zjacić-Rotkvić V and Kaštelan Z (2007). Could diabetic retinopathy be an autoimmune disease? Med. Hypotheses 68: 1016-1018. http://dx.doi.org/10.1016/j.mehy.2006.05.073

King GL (2008). The role of inflammatory cytokines in diabetes and its complications. J. Periodontol. 79 (Suppl): 15271534.http://dx.doi.org/10.1902/jop.2008.080246

Koleva-Georgieva DN, Sivkova NP and Terzieva D (2011). Serum inflammatory cytokines IL-1beta, IL-6, TNF-alpha and VEGF have influence on the development of diabetic retinopathy. Folia Med. (Plovdiv) 53: 44-50.http://dx.doi. org/10.2478/v10153-010-0036-8

Krieglstein CF and Granger DN (2001). Adhesion molecules and their role in vascular disease. Am. J. Hypertens. 14: S 44-S54.

Liu Y, Biarnés Costa M and Gerhardinger C (2012). IL-1 $\beta$ is upregulated in the diabetic retina and retinal vessels: cellspecific effect of high glucose and IL-1 $\beta$ autostimulation. PLoS One 7: e36949. http://dx.doi.org/10.1371/journal. pone. 0036949

Malone JI, Morrison AD, Pavan PR and Cuthbertson DD; Diabetic Control and Complications Trial (2001). Prevalence and significance of retinopathy in subjects with type 1 diabetes of less than 5 years' duration screened for the diabetes control and complications trial. Diabetes Care 24: 522-526. http://dx.doi.org/10.2337/diacare.24.3.522

Moore TC, Moore JE, Kaji Y, Frizzell N, et al. (2003). The role of advanced glycation end products in retinal microvascular leukostasis. Invest. Ophthalmol. Vis. Sci. 44: 4457-4464.http://dx.doi.org/10.1167/iovs.02-1063

Morsy MD, Hassan WN and Zalat SI (2010). Improvement of renal oxidative stress markers after ozone administration in diabetic nephropathy in rats. Diabetol. Metab. Syndr. 2: 29. http://dx.doi.org/10.1186/1758-5996-2-29

Myśliwiec M, Balcerska A, Zorena K, Myśliwska J, et al. (2008). The role of vascular endothelial growth factor, tumor necrosis factor alpha and interleukin-6 in pathogenesis of diabetic retinopathy. Diabetes Res. Clin. Pract. 79: 141146. http://dx.doi.org/10.1016/j.diabres.2007.07.011

Noma H, Funatsu H, Yamashita H, Kitano S, et al. (2002). Regulation of angiogenesis in diabetic retinopathy: possible balance between vascular endothelial growth factor and endostatin. Arch. Ophthalmol. 120: 1075-1080.http://dx.doi. org/10.1001/archopht.120.8.1075

Powell ED and Field RA (1964). Diabetic retinopathy and rheumatoid arthritis. Lancet 2: 17-18.

Semeraro F, Cancarini A, Morescalchi F, Romano MR, et al. (2014). Serum and intraocular concentrations of erythropoietin and vascular endothelial growth factor in patients with type 2 diabetes and proliferative retinopathy. Diabetes Metab. 40: 445-451.http://dx.doi.org/10.1016/j.diabet.2014.04.005

Spranger J, Kroke A, Möhlig M, Hoffmann K, et al. (2003). Inflammatory cytokines and the risk to develop type 2 diabetes: results of the prospective population-based European Prospective Investigation into Cancer and Nutrition (EPIC)-Potsdam Study. Diabetes 52: 812-817.http://dx.doi.org/10.2337/diabetes.52.3.812 
Stadlbauer TH, Eisele A, Heidt MC, Tillmanns HH, et al. (2008). Preconditioning with ozone abrogates acute rejection and prolongs cardiac allograft survival in rats. Transplant. Proc. 40: 974-977. http://dx.doi.org/10.1016/j. transproceed.2008.03.036

Storkebaum E, Lambrechts D and Carmeliet P (2004). VEGF: once regarded as a specific angiogenic factor, now implicated in neuroprotection. BioEssays 26: 943-954. http://dx.doi.org/10.1002/bies.20092

UK Prospective Diabetes Study Group (1998). Intensive blood-glucose control with sulphonylureas or insulin compared with conventional treatment and risk of complications in patients with type 2 diabetes (UKPDS 33). Lancet 352: 837-853. http://dx.doi.org/10.1016/S0140-6736(98)07019-6

Vandanmagsar B, Youm YH, Ravussin A, Galgani JE, et al. (2011). The NLRP3 inflammasome instigates obesity-induced inflammation and insulin resistance. Nat. Med. 17: 179-188. http://dx.doi.org/10.1038/nm.2279

Wainstein J, Feldbrin Z, Boaz M and Harman-Boehm I (2011). Efficacy of ozone-oxygen therapy for the treatment of diabetic foot ulcers. Diabetes Technol. Ther. 13: 1255-1260. http://dx.doi.org/10.1089/dia.2011.0018

Wiwanitkit V (2011). IL-2 and IFN-gamma and diabetic retinopathy. Graefes Arch. Clin. Exp. Ophthalmol. 249: 459, author reply 461-462.http://dx.doi.org/10.1007/s00417-010-1449-z

Yuuki T, Kanda T, Kimura Y, Kotajima N, et al. (2001). Inflammatory cytokines in vitreous fluid and serum of patients with diabetic vitreoretinopathy. J. Diabetes Complications 15: 257-259. http://dx.doi.org/10.1016/S1056-8727(01)00155-6

Zhang X, Saaddine JB, Chou CF, Cotch MF, et al. (2010). Prevalence of diabetic retinopathy in the United States, 20052008. JAMA 304: 649-656. http://dx.doi.org/10.1001/jama.2010.1111

Zhang XL, Wen L, Chen YJ and Zhu Y (2009). Vascular endothelial growth factor up-regulates the expression of intracellular adhesion molecule-1 in retinal endothelial cells via reactive oxygen species, but not nitric oxide. Chin. Med. J. (Engl.) 122: 338-343. 